\title{
Surgical management of bilateral cataracts in a patient with congenital iris coloboma
}

\author{
Wojciech Omulecki, Magdalena Kucharczyk-Pośpiech \\ Department of Ophthalmology, Medical University of Lodz, Poland \\ Medical University Barlicki Hospital No.1, Lodz, Poland
}

\begin{abstract}
The term iris coloboma refers to a hole or fissure in the iris from a congenital malformation or an acquired process. Closure defects can involve the iris, ciliary body, lens, retina, choroid and optic nerve. Eyes with congenital colobomata and cataracts are at greater risk for complications during cataract surgery. Dense brunescent cataracts represent a major challenge for surgeons.

A 78-year-old patient presented to our office due to visual impairment in both eyes. The visual acuity in the right eye was counting fingers and was 0.2 in the left eye. Iris and chorio-retinal colobomata were seen in both eyes inferiorly. A dense brunescent cataract was present in the right eye and a brunescent but less advanced cataract in the left eye. We decided to perform ECCE
\end{abstract}

in the right eye and phacoemulsification in the left eye. A foldable intraocular lens was implanted in both eyes. Coloboma repair was performed by suturing the iris sphincter with a single polypropylene suture. The vision and photophobia of the patient were improved in both eyes. The best corrected visual acuity was 0.3 in the right eye and 0.5 in the left eye post-operatively. The photophobia has significantly decreased. The patient's levels of satisfaction and comfort were very good. The surgical treatment of cataracts in eyes with iris coloboma may be very effective. The choice of cataract removal method should be made taking into consideration the cataract severity and nuclear sclerosis. ECCE should be considered in cases with dense brunescent cataracts. KEY WORDS: congenital iris coloboma, cataract, surgical treatment.

\section{OBJECTIVE}

The term coloboma refers to a notch, hole or fissure in any ocular structure from a congenital malformation or an acquired process. Closure defects can involve the iris, ciliary body, lens, retina, choroid and optic nerve.

Eyes with congenital colobomata and cataracts are at greater risk for complications during cataract surgery because of ocular malformations resulting from embryological maldevelopment. Dense brunescent cataracts represent a major challenge for surgeons. Nucleus management in hard cataracts is more difficult with phacoemulsification than with ECCE. Early postoperative complications include hyphema, increased intraocular pressure and uveitis. The aims of surgical treatment in these cases are to improve the visual acuity and photophobic condition.

\section{INTRODUCTION}

A coloboma (from the Greek koloboma, meaning defect) is a hole in one of the structures of the eye, such as the iris, retina, choroid, or optic disc. The hole is present from birth (except for one case, where it developed within the first few months of the child's life) and can be caused when a gap called the choroid fissure, which is present during early stages of prenatal development, fails to close up completely before a child is born. The classical description in medical literature is of a key-hole shaped defect. A coloboma can occur in one eye (unilateral) or both eyes (bilateral). Most cases of coloboma affect only the iris. The level of visible impairment of those with a coloboma can range from having no vision problems to being able to see only light or dark, depending on the position and extent of the coloboma (or colobomata if more than one is present) [1-4].

The number of cases is around 0.5 to 0.7 per 10000 births, making it a relatively rare condition. Nakamura et al., in a large population-based study, found that the annual incidence was 2.4 per 100000 residents ( $<19$ years old), which means the prevalence of 1 in 2077 live births. Sixty-seven percent had unilateral involvement. Twelve patients had involvement of the anterior segment only, 39\% of the posterior segment only, and $24 \%$ of both. Fifty-eight percent had other ocular disorders, including amblyopia (33\%) and strabismus (30\%) [5]. 


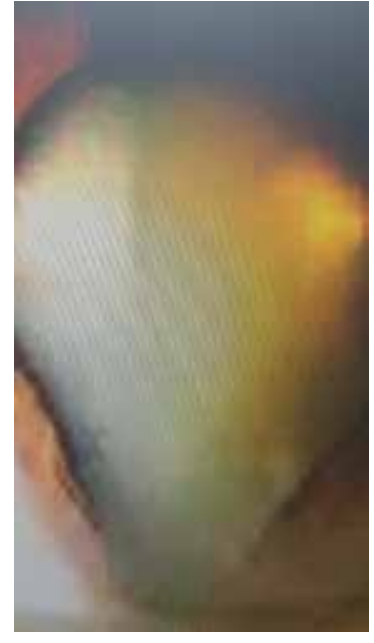

Figure 1. Iris coloboma and dense brunescent cataract were present in the right eye
Visual effects may differ depending on the size and location of the coloboma. If only a small part of the iris is missing, the vision may be normal. When a large part of the retina or optic nerve is missing, the vision may be poor. Commonly posterior colobomata affect the inferior retina, with a resultant deficit in the superior visual field. Sometimes, the eye may be reduced in size, a condition called microphthalmia. Glaucoma, nystagmus, scotoma, or strabismus may also occur. Coloboma can be associated with a mutation in the PAX2 gene. Eye abnormalities have been shown to occur in over $90 \%$ of children with fetal alcohol syndrome $[6,7]$.

Coloboma of the iris may be treated in different ways. A simple cosmetic solution is a specialized cosmetic contact lens with an artificial pupil aperture. Surgical repair of the iris defect is also possible [8-11].

Vision can be improved with glasses, contact lenses or even laser eye surgery but may be limited if the retina is affected $[1,2,12]$.

\section{CASE REPORT}

A 78-year-old female patient presented to our office due to visual impairment in both eyes. The visual acuity in the right eye was counting fingers and 0.2 in the left eye. No spectacle correction was useful. The intraocular pressure was $16 \mathrm{~mm} \mathrm{Hg}$ in both eyes. Iris and chorio-retinal colobomata were seen in both eyes inferiorly. A dense brunescent cataract ( 6 on the LOCS III scale) was present in the right eye and a brunescent but less advanced (4 on the LOCS III scale) cataract in the left eye.

Taking into consideration that eyes with congenital colobomata and dense brunescent cataracts represent a major challenge for surgeons, and increase the risk of intraoperative complications, we decided to perform ECCE in the right eye and phacoemulsification in the left eye. A foldable intraocular lens was implanted in both eyes. After phacoemulsification with the placement of an intraocular lens in the capsular bag, coloboma repair was performed by suturing the iris sphincter with a single, straight polypropylene suture. The needle was

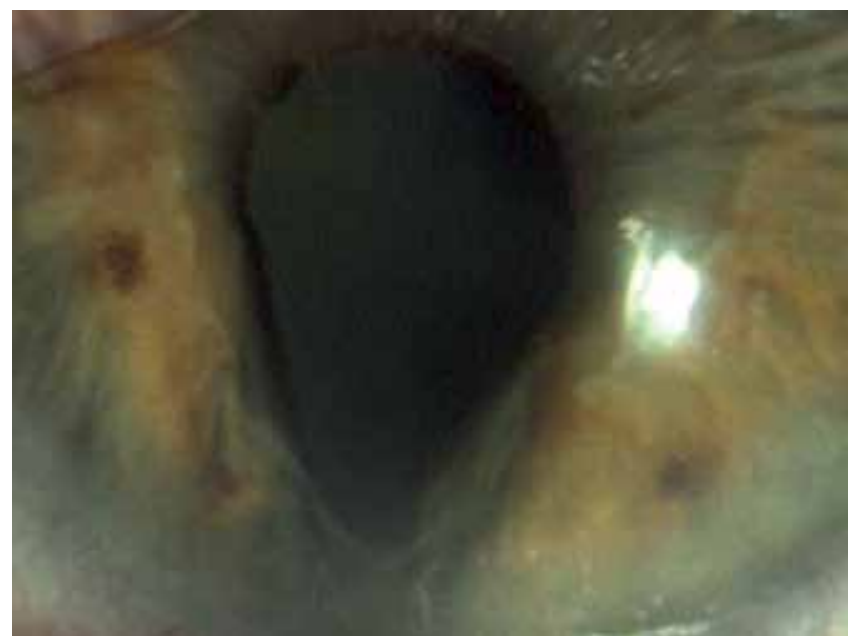

Figure 2. Iris coloboma and less advanced nuclear cataract were present in the left eye

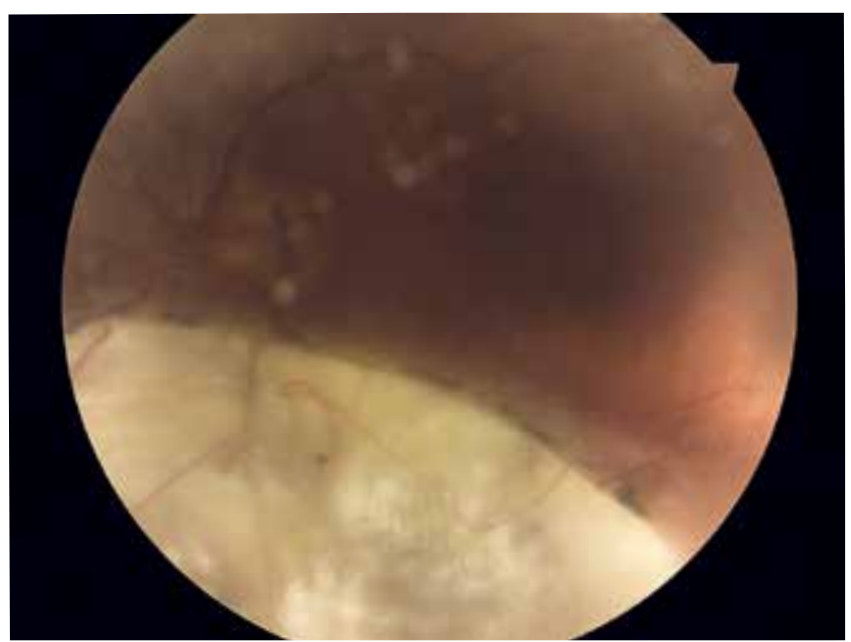

Figure 3. Chorio-retinal colobomata were seen in both eyes inferiorly

inserted in the limbus in the 2 o'clock or 10 o'clock position and then passed through the iris near the sphincter on both sides and then pulled out through the limbus on the opposite site. The threads were pulled out through the incision at 12 o'clock and tied.

The iris colour differs on pre- and post-operative photographs due to different conditions in which they were taken (slit lamp and operating microscope).

\section{RESULTS}

The vision and photophobia of the patient were improved in both eyes. The best corrected visual acuity was 0.3 in the right eye and 0.5 in the left eye post-operatively. There were no severe postoperative complications, despite the small haemorrhage in the anterior chamber which has resolved spontaneously. The patient's levels of satisfaction and comfort were very good $[2,10]$. Unfortunately, there are no descriptions of large groups of patients treated surgically for iris coloboma in the literature. Therefore, the result achieved in our case cannot be compared. 


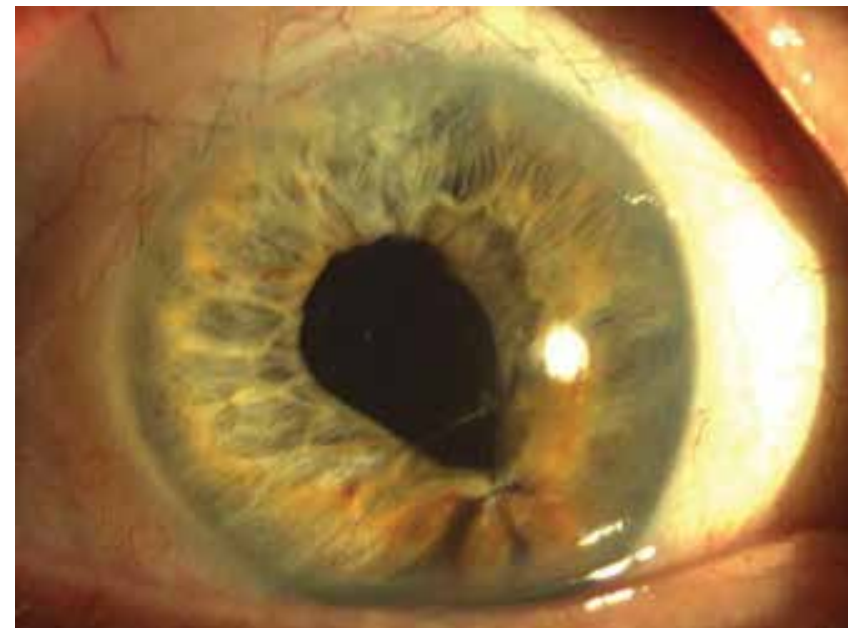

Figure 4. Postoperative appearance of the right eye

\section{CONCLUSIONS}

The surgical treatment of cataracts in eyes with iris coloboma may be very effective. The choice of cataract removal method should be made taking into consideration the cataract severity and nuclear sclerosis. ECCE should be considered in cases with dense brunescent cataracts.

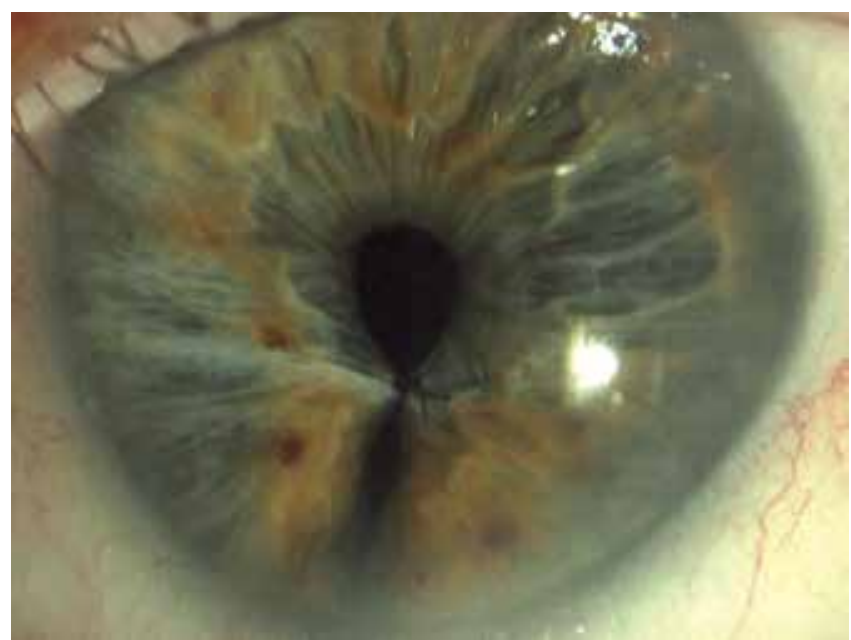

Figure 5. Postoperative appearance of the left eye

\section{DISCLOSURE}

The authors declare no conflict of interest.

\section{References}

1. Blain CL, Bertuzzi D, Brooks S. Uveal coloboma: clinical and basic science update. Curr Opin Ophthalmol 2006; 17: 447-470.

2. Pagon RA. Ocular coloboma. Surv Ophthalmol 1981; 25: 223-236.

3. Maumenee IH, Mitchell TN. Colobomatous malformations of the eye. Trans Am Ophthalmol Soc 1990; 88: 123-135.

4. Onwochei BC, Simon JW, Bateman JB, et al. Ocular colobomata. Surv Ophthalmol 2000; 45: 175-194.

5. Nakamura KM, DiehI NN, Mohney BG. Incidence, ocular findings, and systemic associations of ocular coloboma: a population-based study. Arch Ophthalmol 2011; 129: 69-74.

6. Cunliffe $H E, M C N o e L A$, Ward TA, et al. The prevalence of PAX2 mutations in patients with isolated coloboma or colobomata associated with urogenital anomalies. J Med Genet 1998; 35: 806-812.

7. Strömland K, Pinazo-Durán MD. Ophthalmic involvement in the fetal alcohol syndrome: clinical and animal model studies. Alcohol Alcohol 2002; 37: 2-8.

8. Blackmon DM, Lambert SR. Congenital iris coloboma repair using a modified McCannel suture technique. Am J Ophthalmol 2003; 135: 730-732.

9. Cywiński A, Ferda-Lewińska D. Chirurgia plastyczna wrodzonego ubytku tęczówki modo Cywiński. Ophthatherapy 2018, 5: 46-51

10. Cionni RJ, Karatza EC, Osher RH, Shah M. Surgical technique for congenital iris coloboma repair. J Cataract Refract Surg 2006; 32: 1913-1916.

11. Patnaik B, Kalsi R. Retinal detachment with coloboma of the choroid. Indian J Ophthalmol 1981; 29: 345-349.

12. Porter D. Coloboma treatment. Amer Acad Ophthalmol 2020. Available at: https://www.aao.org/eye-health/diseases/coloboma -treatment. 